\title{
Childhood Fever Knowledge and Management: A Case of Moth- ers with Children under Five Years
}

\author{
Reindolf Anokye ${ }^{1 *}$, Rita Amihere ${ }^{2}$, Patience Abbiaw ${ }^{2}$, Enoch Acheampong ${ }^{1}$, Naomi Gyamfi' and Amy \\ Budu-Ainooson ${ }^{3}$
}

\author{
${ }^{1}$ Department of Community Health, Centre for Disability and Rehabilitation Studies, Kwame Nkrumah \\ University of Science and Technology, Kumasi, Ghana \\ ${ }^{2}$ Department of Nursing, Garden City University College, Kumasi, Ghana \\ ${ }^{3}$ Department of Health Education and Promotion, School of Public Health, Kwame Nkrumah University \\ of Science and Technology, Kumasi, Ghana
}

*Corresponding author: Reindolf Anokye, Department of Community Health, Centre for Disability and Rehabilitation Studies, Kwame Nkrumah University of Science and Technology-Kumasi, Ghana

\begin{abstract}
Background: Most childhood ailments often present with fever which account for the most common reasons why parents seek medical care for their children; particularly, the under-five children. The study aimed to assess the mothers' knowledge of fever in their under-five children and how this is managed at home.
\end{abstract}

Methods: This was a descriptive designed study that used a simple random sampling technique to select 100 participants who were mothers of under-five children who presented to the Kwahu Government Hospital, Atibie over a period of six months. A structured questionnaire comprising of close-ended questions were used to collect data. Both secondary and primary data were collected and analyzed. The primary data was analyzed using SPSS version 16.0.

Results: The mothers described fever as hotness of body $(63 \%)$, shivering $(10 \%)$, child crying $(8 \%)$, child being quiet $(8 \%)$ and sleeping too often $(10 \%)$. More than half of the respondents $(57 \%)$ correctly identified the cause of fever as malaria (39\%) and infections (18\%). Home management of fever involved self-medications (43\%), consulting herbalist $(20 \%)$ as well as tepid sponging (28\%) and visiting nearby hospital $(62 \%)$. Mothers knowledge of childhood fever was statistically significantly associated with their age $(p=0.0001)$, age of the child ( $p=0.04)$, number of children in a family $(p=0.0001)$, and level of education of the mothers $(p=0.0001)$.

Conclusions: Mothers described hotness of the body as fever and knew that malaria and infections causes fever among children. They consulted herbalist among other inappropriate practices in the management of fever.

\section{Keywords}

Childhood fever, Knowledge, Management, Mothers, Children under five

\section{Introduction}

Most childhood ailments often present with fever which account for the most common reasons why parents seek medical care for their children [1]. In the first two years of life, children generally experience between four to six febrile episodes each year [2]. Fever is a common sign of self-limiting viral infections; however they may signify serious illnesses in less than $10 \%$ of cases and bacterial infections in approximately $4 \%$ [3]. The incidence of fever as the major complaint for consultation is reported to be 122 per thousand children up to 1-year-old, and 415 per 1000 children from 1 to 5 -yearold in the Netherlands [4]. Studies from the USA reported that about $30 \%$ of children seen by paediatricians in practice were as a result of fever [5].

In Africa, higher incidence of fever has been recorded in the rural part of Senegal with $20 \%$ of children getting fever every month. In Mali, prevalence of fever for a day was $6.2 \%$ in dry season and $12.8 \%$ in rainy season while in rural parts of Guinea the prevalence of fever was $23 \%$ in under-five children and in Kenya it was 6\% [6]. Fever

Citation: Anokye R, Amihere R, Abbiaw P, Acheampong E, Gyamfi N, et al. (2018) Childhood Fever Knowledge and Management: A Case of Mothers with Children under Five Years. Int J Pediatr Res 4:044. doi.org/10.23937/2469-5769/1510044

Accepted: November 13, 2018: Published: November 15, 2018

Copyright: (c) 2018 Anokye R, et al. This is an open-access article distributed under the terms of the Creative Commons Attribution License, which permits unrestricted use, distribution, and reproduction in any medium, provided the original author and source are credited. 
accounts for over $60 \%$ of pediatric outpatients' visits in Ghana and other Sub-Saharan African countries [7].

Huda, et al. [8], indicated that mothers usually recognize fever by the general appearance of the child and they also determine how to treat fever in their children with self-medication $[9,10]$. According to Stagnara, et al. [11], most parents repeatedly treat fever in their children by self-medication before seeking the opinion of a physician. Fever is potentially harmful if inappropriately managed and it has been reported to have some potentially harmful effects if not well managed [12]. Parents need consistent evidence-based information about childhood fever management [13] which can be achieved through education about fever and improving access to primary care [14].

At The Kwahu Government Hospital at Atibie, 1034 cases of childhood fever were reported between 2014 and 2016 , of which $31-43 \%$ febrile convulsion [15]. Febrile convulsion is the most common childhood fever in under five children and is one of the causes of pediatric hospital admissions in Ghana [16]. The study aimed to assess mothers' knowledge of fever and its management in under-five children in Atibie, Ghana.

\section{Methods}

\section{Study design and setting}

A descriptive study design was adopted employing a quantitative approach. The study was carried out at The Kwahu Government Hospital. The hospital is one of two district hospitals in the Kwahu ridge area. It serves an estimated population of about 230,000 people from over 200 Communities within the district.

\section{Design of data collection tools}

The data collection tool used in this study was self-designed questionnaire. A structured questionnaire comprising of close-ended questions and designed using the English Language were used to collect data. The questionnaire was divided into three sections where information was gathered on the demographics of the child and their mothers, mothers' knowledge of fever, and home management of fever. Questions related to the demographics were open-ended. For close-ended questions there were pre-determined responses for the participants to pick from. A pre-test of the questionnaires was conducted at The Kumasi South Hospital which has the same characteristics like study site. The Cronbach's Alpha test was used to measure the internal consistency of the instruments. For this study the scores obtained were 0.81 for mothers' knowledge of fever and 87 for home management of fever. The instruments were therefore deemed reliable and it was further evaluated to correct grammatical errors and typographical errors.

\section{Data collection}

Data was collected within a period of 6 months (No- vember 2016 to April 2017) which increased the possibility of having varied answers and 4 research assistants were included in data collection. A pretesting was done with a sample of the respondents before the actual administration of the questionnaires to minimize bias in the study. Questionnaires were administered to respondents by the researchers and their assistants. The questions were read out to the mothers and the interviewers entered the responses into the questionnaire. The questionnaire was also read in any other language respondents preferred and could easily understand.

\section{Sampling and Sample Size Determination}

The sample size was calculated using Yamane [17] formula. For this study, $90 \%$ confidence level and precision of $10 \%(P=0.10)$ were used.

Equation; $n=\frac{N}{1+N(e)^{2}}$

Where $n$ is the sample size, $N$ is the population size, and $e$ is the level of precision. An average of 20,000 women with children under five years report to the facility with fever annually. Therefore, this formula was applied to achieve the sample for the study.

$$
\begin{aligned}
& N=20,000 \\
& 1+N(e)^{2}=1+20,000(.10)^{2} \\
& n=\frac{20000}{1+20000(.10)^{2}} \\
& n=100
\end{aligned}
$$

In selecting the sample, a simple random sampling technique was applied. This method selected by chance or none zero selection of mothers of children under five years. The number of mothers with under five children who visited the facility were counted each day and based on the numbers for the day, random numbers from a prepared random number table was assigned to them. After that, 5 random numbers were selected each day of data collection within six (6) months till the sample size was attained.

\section{Statistical analysis}

The data was analyzed using SPSS version 16.0 and presented using both descriptive and inferential statistics displayed in frequency bar graphs and tables. The use of mean, standard deviation, frequency and percentages constituted the descriptive aspects of the statistics employed for the analysis of data. Mean, standard deviation, frequency and percentages were used in describing the demographic data. Chi-square tests were used to assess association between Age of mother, Age of child, Marital status, Number of children, Level of Education, Number of children under five years and knowledge of fever.

\section{Ethics for the study}

A verbal informed consent was sought before admin- 
Table 1: Characteristics of the study sample.

\begin{tabular}{|c|c|c|c|c|}
\hline Variables & Characteristics & Frequency & Percentage & \\
\hline \multirow[t]{5}{*}{ Age } & $13-18$ years & 18 & 3 & \multirow{5}{*}{$\begin{array}{l}\text { Mean }=31.36 \\
S D=7.97\end{array}$} \\
\hline & 19-24 years & 56 & $56 \%$ & \\
\hline & $25-30$ years & 10 & $10 \%$ & \\
\hline & $31-40$ years & 8 & $8 \%$ & \\
\hline & More than 40 years & 8 & $8 \%$ & \\
\hline \multicolumn{5}{|c|}{ Age of child } \\
\hline & Less than 1 year & 14 & $14 \%$ & \multirow{3}{*}{$\begin{array}{l}\text { Mean = } 2.08 \\
S D=1.12\end{array}$} \\
\hline & $1-2$ years & 26 & $26 \%$ & \\
\hline & $3-4$ years & 60 & $60 \%$ & \\
\hline \multicolumn{5}{|c|}{ Marital status } \\
\hline & Married & 54 & $54 \%$ & \\
\hline & Single & 24 & $24 \%$ & \\
\hline & Divorced & 13 & $13 \%$ & \\
\hline & Co-habiting & 9 & $9 \%$ & \\
\hline \multicolumn{5}{|c|}{ Number of children } \\
\hline & One & 31 & $31 \%$ & \\
\hline & Two & 25 & $25 \%$ & \\
\hline & Three & 34 & $34 \%$ & \\
\hline & More than three & 10 & $10 \%$ & \\
\hline \multicolumn{5}{|c|}{ Level of education } \\
\hline & Basic school & 37 & $37 \%$ & \\
\hline & Secondary/SHS/O level & 27 & $27 \%$ & \\
\hline & Tertiary & 5 & $5 \%$ & \\
\hline & No formal education & 31 & $31 \%$ & \\
\hline \multicolumn{5}{|c|}{ Number of children under five years } \\
\hline & One & 84 & $84 \%$ & \\
\hline & Two & 14 & $14 \%$ & \\
\hline & Three & 27 & $2 \%$ & \\
\hline
\end{tabular}

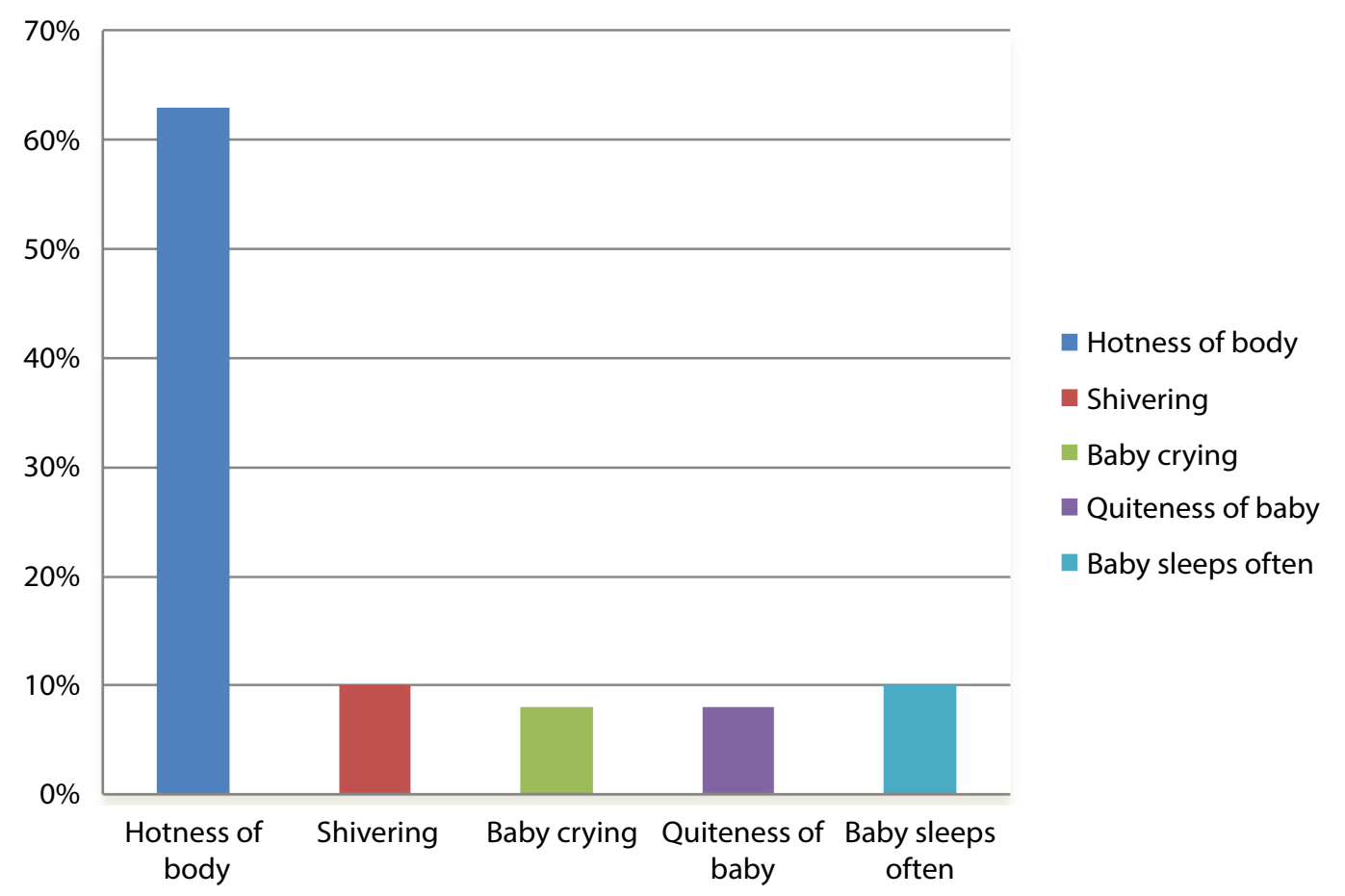

Figure 1: Description of fever.

istration of the questionnaire. Verbal consent was taken from respondents because a good number of them could not read or write. The process was approved by the ethics committee after explaining why such approach was used. Approval was sought from the admin- istrators of the hospital before the facility was used and also ethical clearance was obtained from the committee on Human Research Publications and Ethics (CHRPE) of the Kwame Nkrumah University of Science and Technology before the study was carried out. 


\section{Results}

\section{Demographic characteristics of mothers}

Table 1 shows Characteristics of the study sample and majority of the mothers were $19-24$ years old (56\%), married (54\%), and had only one child (84\%). Majority of the children were 3-4 years old (60\%). The mean age of the mothers was $31.36 \pm 7.97$ years, while the mean age for the children was $2.08 \pm 1.12$ years.

\section{Mother's knowledge of fever}

Description of fever by mothers as shown in Figure 1 suggests that most mothers (63\%) described hotness of the body of a child as fever. Others described it as shivering $(10 \%)$ as well as quietness of baby $(8 \%)$, baby crying ( $8 \%$ ) and baby sleeps often (10\%).

Respondents shared their views on what causes fever as displayed in Figure 2. From their responses, some said it is caused by infections (18\%) but most of the mothers (39\%) were of the opinion that fever was cause by malaria. Others also mentioned overeating (6\%) as well as evil spirits (11\%).

From the Table 2, the level of mother's knowledge about fever differed significantly with demographic characteristics such as Age of mother $(p=0.0001)$, Age of child $(p=0.04)$, Number of children $(p=0.0001)$ and Level of Education $(p=0.0001)$.

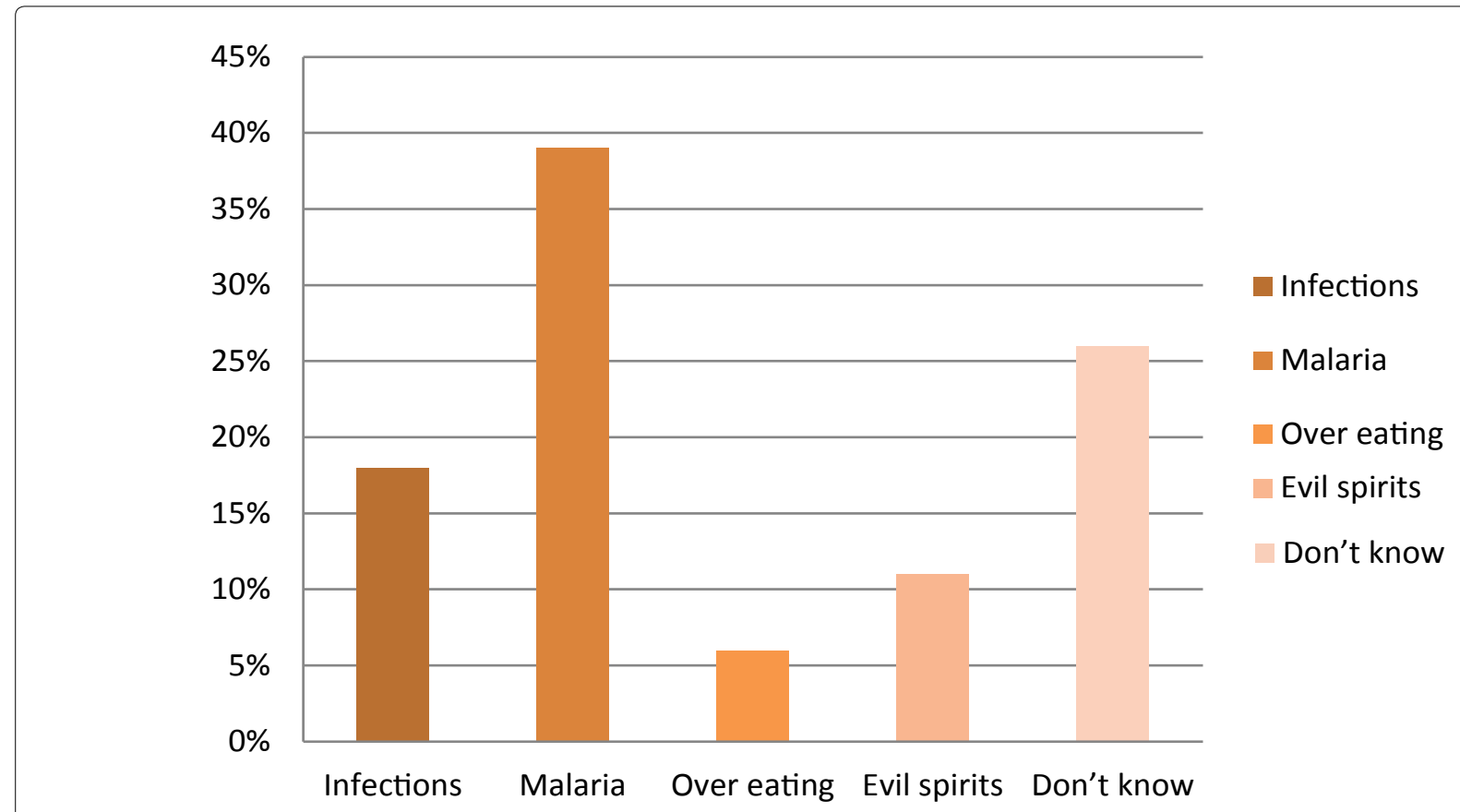

Figure 2: Causes of fever.

Table 2: Mothers demographic characteristics and knowledge of fever.

\begin{tabular}{|c|c|c|c|}
\hline Mothers characteristics & $\begin{array}{l}\text { Knowledge of fever } \\
\text { (Good) ( }=57 \text { ) }\end{array}$ & $\begin{array}{l}\text { Knowledge of fever } \\
\text { (Poor) }(n=43)\end{array}$ & P- value ${ }^{*}$ \\
\hline \multicolumn{4}{|l|}{ Age } \\
\hline$<30$ years & 17 & 32 & \multirow[t]{2}{*}{0.0001} \\
\hline$\geq 30$ years & 40 & 11 & \\
\hline \multicolumn{4}{|l|}{ Age of child } \\
\hline$<3$ years & 14 & 24 & \multirow[t]{2}{*}{0.04} \\
\hline$\geq 3$ years & 43 & 19 & \\
\hline \multicolumn{4}{|l|}{ Marital status } \\
\hline Married & 27 & 20 & \multirow[t]{2}{*}{0.356} \\
\hline Not married & 30 & 23 & \\
\hline \multicolumn{4}{|l|}{ Number of children } \\
\hline$<3$ & 13 & 10 & \multirow[t]{2}{*}{0.0001} \\
\hline$\geq 3$ & 44 & 33 & \\
\hline \multicolumn{4}{|l|}{ Level of education } \\
\hline Formal education & 41 & 6 & \multirow[t]{2}{*}{0.0001} \\
\hline No formal education & 16 & 37 & \\
\hline \multicolumn{4}{|c|}{ Number of children under five years } \\
\hline$<3$ & 24 & 23 & \multirow[t]{2}{*}{0.343} \\
\hline$\geq 3$ & 33 & 20 & \\
\hline
\end{tabular}




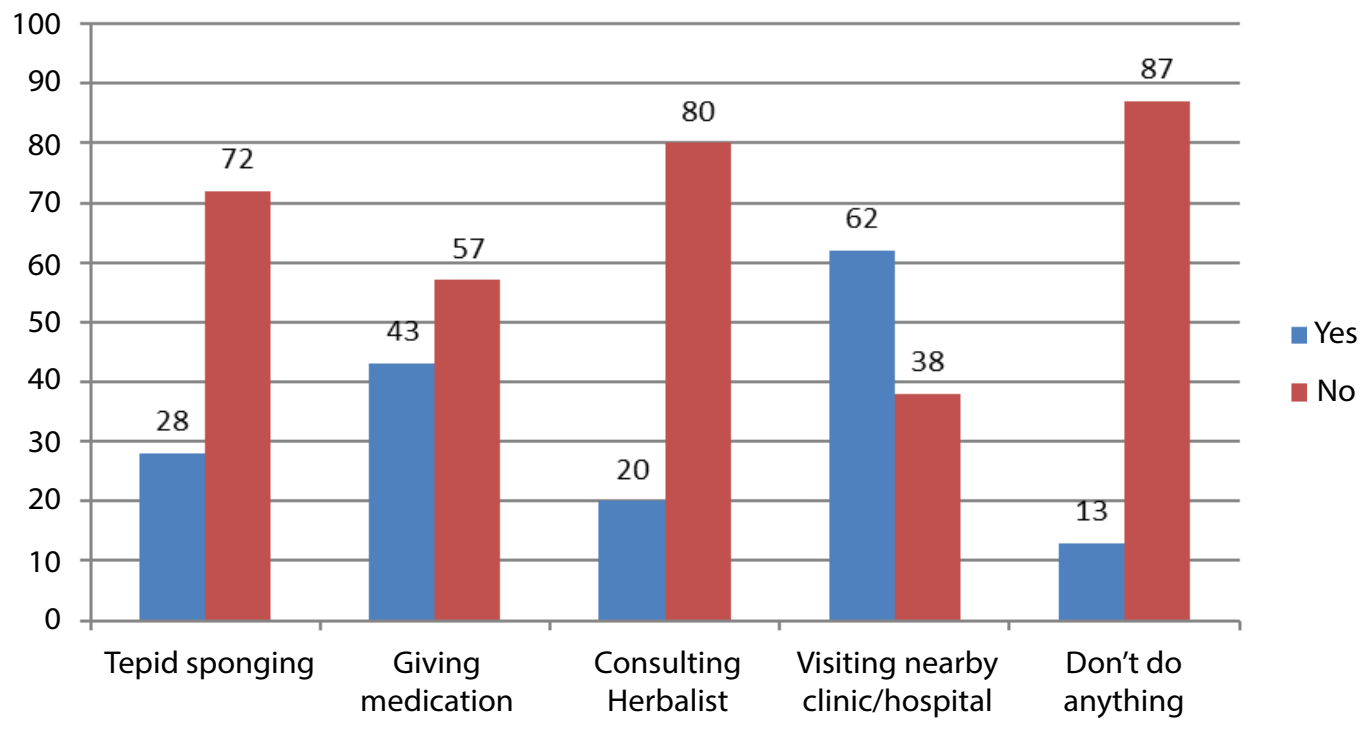

Figure 3: Fever management practices.

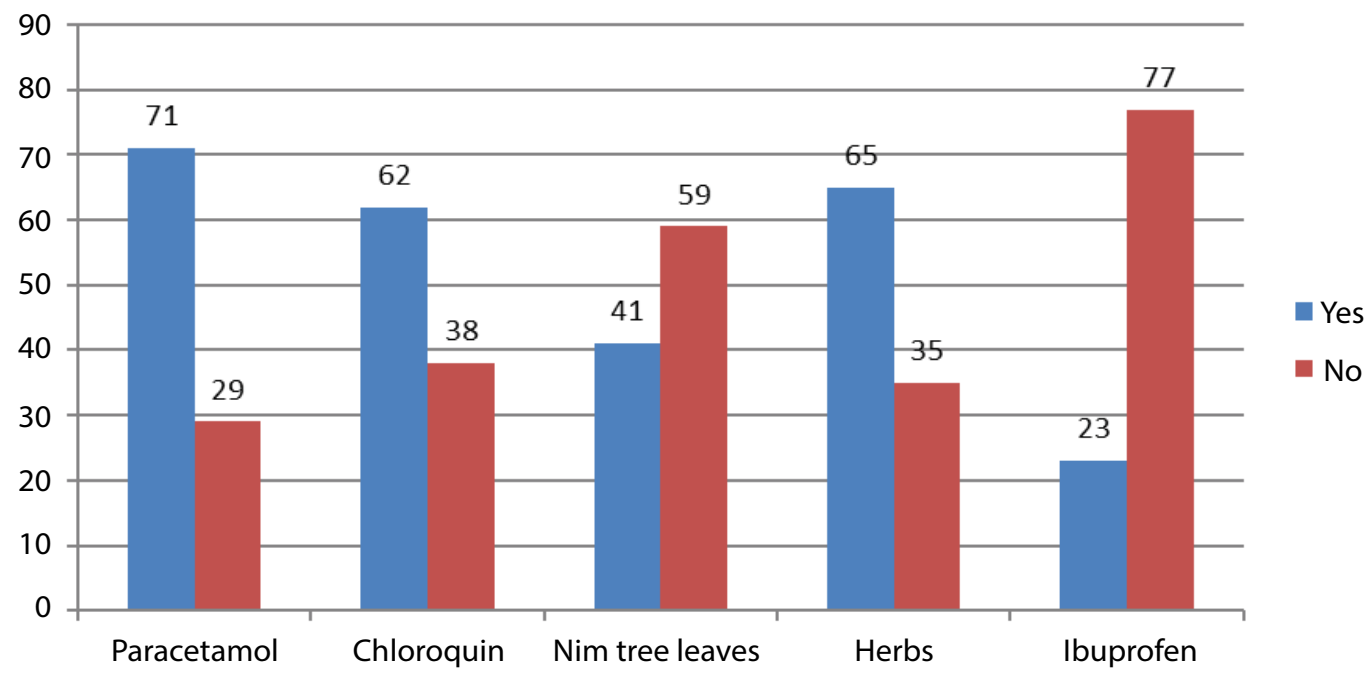

Figure 4: Medications for treating fever.

\section{Fever management practices}

Figure 3 shows mothers fever management practices. From the figure, visiting nearby clinic/hospital, tepid sponging as well as giving children medication when they had fever were some of the frequently used fever management practices among mothers.

Figure 4 displays Medications for treating fever among mothers. The figure shows that more than half of the respondents had administered herbs (65\%), paracetamol $(71 \%)$ and chloroquine $(62 \%)$ as medication to manage fever.

\section{Discussion}

This study examined the knowledge and management of fever among mothers with children under five years. The study assessed the mother's knowledge on fever, the causes of fever and various management practices. The findings revealed that, more than half of the mothers described fever as hotness of the body.
This indicates that hotness of the body was usually attributed to fever in the study location. This supports the findings of Oshikoya and Senbanjo [7] who reported that most of the mothers (83.3\%) perceived fever as the hotness of the whole body of the patient.

A proportion of the respondents of this study were of the view that fever is caused by overeating (6\%) as well as evil spirits (11\%). This suggests that there are several misconceptions about the causes of fever. Similarly, Taveras, et al. [14] reported that Latino parents were more likely to believe that certain Latino folk illnesses ( $m a l$ de ojo, empacho (indigestion or Gl malaise) and mollera caida) causes fever. Mal de ojo occurs when a person with "strong eyes" intentionally or unintentionally looks at a child while Mollera caida or fallen fontanelle is believed to occur when the breast or bottle is removed too rapidly from an infant's mouth or when the infant is bounced or tossed around. The misconceptions about the causes of fever may be attributed to socio-cultural believes. 
In another study, Huda, et al. [8] reported that majority of respondents (81.6\%) believed that teething causes fever in children. However, we observed that most of our respondents (39\%) identified malaria as the commonest cause of fever in children.

The age of mother, age of child, number of children and level of education were found to be significantly associated with mothers' knowledge of fever. The significant association of mothers' knowledge of fever and their level of education corroborates other studies from different populations [18-22].

In our study, the proportion of mothers who will administer medication for fever in their children was $43 \%$. This was far lower than the $88 \%$ reported in Australia and even far lower than the $94 \%$ reported in France $[11,13]$. The percentage gap in the medication use may be due to their location and access to drugs and to some extent their knowledge in other methods of managing the condition. A number of the respondents in the study reported that fever was caused by spirits. It is likely that these people may focus management on dealing with the spirit behind the sickness. Regarding use of medications to treat fever, antipyretics such as paracetamol and Ibuprofen were used. Health professionals frequently recommend treatment regimens for children with fever that either combine or alternate paracetamol and ibuprofen [23,24]. However, the consequences of under- and over-treatment with antipyretics including mucosal lesions, gastrointestinal discomfort such as dyspepsia, and severe gastrointestinal complications such as perforated ulcer, gastrointestinal bleeding has been reported [25].

Furthermore, the findings that Paracetamol and chloroquine were also medications used by some of the mothers to manage fever is consistent with other studies who found most mothers managing fever with paracetamol $[11,26]$. This indicates that these medications are the easiest to access either through over the counter drug sellers or the environment. Ibuprofen was mentioned by a small number of respondents. However, in the study of Stagnara, et al. [11], ibuprofen was one of the medications mentioned most often by respondents for managing fever.

Also, more than half of the respondents had applied herbal concoctions to treat fever in their children. Herbs have potentially unexpected effects such as toxicity [27]. An interaction may involve having the herb component to cause an increase/decrease in the amount of drug in the blood stream $[28,29]$. The high rate of the use of herbal concoctions may be due to the fact that the study was conducted in a peri-urban area where most mothers are not highly educated, poor and may not have access to health facilities as compared to those in the larger cities.

It is appropriate to present a febrile child to the hospital or a physician, $62 \%$ of the respondent's in this study presented a febrile child to the hospital/clinic. A higher proportion of mothers $(85.7 \%)$ in a study on knowledge and management of fever among Moroccan parents consulted the general practitioner or paediatrician when fever persisted [30]. The reason behind the number of people visiting hospital or a physician when their child had fever may probably be due to the preference for expert management.

The study made use of 100 respondents from the study area based on the sampling formula and framework selected. Only those mothers who already had access to health care were sampled. Those without access may have less fever knowledge and be at greater risk for adverse outcomes. A larger proportion of respondents may provide the kind of information that is representative of the actual situation. Also, the illiteracy level in the study area made it difficult to recruit respondents for the study since most of them were not used to participating in such studies and did not know its relevance.

\section{Conclusion}

In this descriptive study, mothers described hotness of the body as fever and perceived malaria as the major cause of fever among children. The fever management practices frequently utilised by the mothers included tepid sponging, applying herbal concoction as well as giving children medication and visiting the hospital/ clinic. Most of the mothers administered herbs, paracetamol and chloroquine as medication to manage fever. The age of mother, age of child, number of children and level of education were found to be significantly associated with mothers' knowledge of fever. Based on the findings, it is recommended that The Ministry of health should intensify education on childhood fever and channel it through the print, community information centres and electronic media to inform mothers on issues related to causes, early and late signs and management of fever. Parents should also be educated on the effect of fever, especially if not managed on time; highlighting the importance of early management that has to do with fever. Public Health nurses should intensify campaigns on fever to eliminate the negative religious-cultural perceptions and believes mothers attached to fever and its causes.

\section{Authors' Contributions}

The conception and design as well as data collection of the study were taken care of by the first, second and third authors (R. Anokye, R. Amihere and PA) The secondary data compilation and review of the literature was done by the first author. The fourth author (AE) read the entire manuscript and improved the write-up. All the authors contributed to the data analysis, design and preparation of the manuscript. All authors read and approved the final manuscript and have all agreed to its submission for publication. 


\section{Acknowledgments}

We wish to express our profound gratitude to the staff of the School of Nursing, Garden City University College as well as staff and management of The Kwahu Government Hospital and all mothers who participated in this study. We further wish to thank all who have contributed to knowledge in the area of fever among children as well.

\section{References}

1. Kelly L, Morin K, Young D (1996) Improving caretakers' knowledge of fever management in preschool children: Is it possible? Journal of Pediatric Health Care 10: 167-173.

2. McCarthy PL (1999) Fevers and the evaluation of the child with who has fever. Ambulatory Pediatrics 1999: 157-163.

3. Knoebel EE, Narang AS, Ey JL (2002) Fever: To treat or not to treat. Clinical Pediatrics 41: 9-16.

4. Penning C, van der Linden JH, Tibboel D, Evenhuis HM (2011) Is the temporal artery thermometer a reliable instrument for detecting fever in children? J Clin Nurs 20: 1632-1639.

5. Van der Jagt EW (1997) Fever. In: Hoekelman RA, Adam $\mathrm{H}$, Nelson N, Weitzman M, Wilson MH, Primary Pediatric Care. St Louis: Mosby, 959-966.

6. Diallo $A B$, De Serres $G$, Béavogui $A H$, Lapointe $C$, Viens $P$ (2001) Home care of malaria-infected children of less than 5 years of age in a rural area of the Republic of Guinea. Bulletin of the World Health Organization 79: 28-32.

7. Oshikoya K, Senbanjo I (2008) Fever in children: Mothers' perceptions and their home management. Iran J Pediatr 18: 229-236.

8. Huda KA, Nadia A, Amani A (2007) To survey mothers about their knowledge concerning fever in children, how they manage it at home. Primary Health Care, Shamiya Clinic, Capital Health Region, Kuwait. The Kuwait Medical Journal 347-349.

9. Simmons CP, Chau TN, Thuy TT, Tuan NM, Hoang DM, et al. (2007) Maternal antibody and viral factors in the pathogenesis of dengue virus in infants. J Infect Dis 196: 416-424.

10. Doan Q, Enarson P, Kissoon N, Klassen TP, Johnson DW (2009) Rapid viral diagnosis for acute febrile respiratory illness in children in the emergency department. Cochrane Database Syst Rev.

11. Stagnara J, Vermont J, Dürr F, Ferradji K, Mege L, et al. (2005) Parents attitudes towards childhood fever, a cross-sectional survey in the Lyon metropolitan area (202 cases). Presse Med 34: 1129-1136.

12. Dinarello CA, Cannon JG, Wolf S (1988) New concepts on the pathogenesis of fever. Rev Infect Dis 10: 168-189.

13. Walsh A, Edwards H, Fraser J (2008) Parents' childhood fever management: Community survey and instrument development. J Adv Nurs 63: 376-388.
14. Junqueira AL, Tavares VR, Martins RM, Frauzino KV, da Costa e Silva AM, et al. (2010) Safety and immunogenicity of hepatitis $B$ vaccine administered into ventrogluteal vs. anterolateral thigh sites in infants: A randomised controlled trial. Int J Nurs Stud 47: 1074-1079.

15. (2016) Statistics from patient's folders and records from the hospital. The Kwahu Government Hospital.

16. (2013) Ghana health service annual report. reproductive and child health unit, Public health unit, Ghana.

17. Yamane $T$ (1967) Elementary sampling theory. Prentice-Hall, Englewood Cliffs, London.

18. Taveras EM, Durousseau S, Flores G (2004) Parents' beliefs and practices regarding childhood fever: A study of a multiethnic and socioeconomically diverse sample of parents. Pediatr Emerg Care 20: 579-587.

19. Al-Eissa YA, al-Zamil FA, al-Sanie AM, al-Salloum AA, al-Tuwaijri HM, et al. (2000) Home management of fever in children: Rational or ritual? Int J Clin Pract 54: 138-142.

20. Al-Nouri L, Basheer K (2006) Mothers' perceptions of fever in children. J Trop Pediatr 52: 113-116.

21. Mackowiak PA (1998) Concepts of fever. Arch Intern Med 158: $1870-1881$.

22. Poirier MP, Collins EP, McGuire E (2010) Fever phobia: A survey of caregivers of children seen in a pediatric emergency department. Clin Pediatr (Phila) 49: 530-534.

23. Wong T, Stang AS, Ganshorn H, Hartling L, Maconochie IK, et al. (2014) Cochrane in context: Combined and alternating paracetamol and ibuprofen therapy for febrile children. Evid Based Child Health 9: 730-732.

24. Mistry N, Hudak A (2014) Combined and alternating acetaminophen and ibuprofen therapy for febrile children. Paediatr Child Health 19: 531-532.

25. Plaisance KI (2000) Toxicities of drugs used in the management of fever. Clin Infect Dis 31: S219-S223.

26. Le TH, Ottosson E, Nguyen TK, Kim BG, Allebeck P (2011) Drug use and self-medication among children with respiratory illness or diarrhea in a rural district in Vietnam: A qualitative study. J Multidiscip Healthc 4: 329-336.

27. Anastasi JK, Chang M, Capili B (2011) Herbal supplements: Talking with your patients. Journal for Nurse Practitioners 7: 29-35.

28. Williamson E, Driver S, Baxter K (2009) Stockley's herbal medicines interactions. Pharmaceutical Press, London.

29. Williamson EM (2003) Drug interactions between herbal medicines and prescription medicines. Drug Saf 26: 10751092.

30. Rkain M, Rkain I, Safi M, Kabiri M, Ahid S, et al. (2014) Knowledge and management of fever among Moroccan parents. Eastern Mediterranean Health Journal 20: 397402. 